\title{
The Effect of Multimedia Glosses on Online Computerized L2 Text Comprehension and Vocabulary Learning of Iranian EFL Learners
}

\author{
Omid Tabatabaei \\ Islamic Azad University, Najafabad Branch, Iran \\ Email: tabatabaeiomid@yahoo.com \\ Nasrin Shams \\ Islamic Azad University, Najafabad Branch, Iran
}

\begin{abstract}
This study investigated the effects of different types of multimedia glosses, namely text, picture, and text plus picture on online computerized L2 text comprehension and vocabulary learning of junior high school students. About 60 female Iranian junior high school students were selected from a population pool of 102 volunteers based on their performance on a standard English proficiency test (Nelson). Afterwards, they were randomly assigned to 4 groups of 15, three gloss groups, subsequently exposed to the research treatment and one control group. Taking advantage of the results of the pilot study, some words of the computerized written texts were glossed and hyperlinked by a computer software program. When the students clicked on hyperlinked words, a new page appeared and showed the word with a definition in English (textual gloss group), a picture (pictorial gloss group), or a combination of both definition and picture (textual plus pictorial gloss group). Participants in each experimental group read the texts under one of the three mentioned conditions. Statistical analyses of the results reveal that 1) all multimedia gloss groups comprehended computerized L2 texts significantly better than the control group, 2) A significant difference between the multimedia gloss groups and the control group in the production of the target vocabulary items was found. 3) The mix gloss group insignificantly outperformed the textual and pictorial gloss groups in computerized L2 text comprehension, and 4) regarding vocabulary learning, the mix gloss group significantly outperformed the other two gloss groups. Hence, the findings of this study indicate that utilizing computers and multimedia glosses can be influential in language teaching in general and online $\mathrm{L} 2$ text comprehension as well as incidental vocabulary learning in particular.
\end{abstract}

Index Terms - L2 text comprehension, online computerized text, gloss, multimedia gloss, vocabulary learning

\section{INTRODUCTION}

Undoubtedly, words are the building blocks of language and the lack of words will surely become an obstacle to the acquisition of other aspects of language including reading, writing, listening and speaking. Thus, how to enlarge vocabulary size and how to use vocabulary in a productive way have become major concerns of L2 learners as well as L2 teachers.

Foreign language vocabulary plays an important role in achieving high-level of reading ability and enhancing comprehension (Anderson \& Freebody, 1981; Markham, 1989; Segalowitz \& Watson, 1995). It is necessary to point out that the relationship between vocabulary acquisition and reading comprehension is not a completely straightforward one. Reading comprehension requires a host of interactive variables, which operate in a complicated unison (Chun \& Plass, 1997). Reading is, thus, dependent not only on vocabulary knowledge, but also on background knowledge, synthesis and evaluation skills and strategies, metacognitive knowledge, and skill monitoring. The relationship between vocabulary knowledge and reading albeit not exclusive remains an important one. Even though some recent studies have been published which challenge this role (Chodkiewicz, 2001; Laufer \& Nation, 2001), it is widely believed that reading is an important source of vocabulary acquisition both in L1 and L2 (Bogaards, 2001; Krashen, 1989; Watanabe, 1997).

According to Krashen (1989), vocabulary acquisition while reading occurs in an incidental way. Even though incidental learning while reading is relatively successful, many researchers report data showing that its efficiency can be enhanced further by rendering the text more comprehensible through usage of glosses or a dictionary, for example (Hulstijn, 1992; Watanabe, 1997).

In the present study, vocabulary learning and reading comprehension in a media environment enhanced with glosses were investigated. Glosses would be substitutes for the traditional dictionary with which the student had to switch focus from the passage to the dictionary with the consequent waste of time and effort. 
Despite the recognition of the importance of vocabulary acquisition, vocabulary learning seems to be a great headache to many language learners. Learners tend to forget newly-remembered words quite soon or they find it rather difficult to use them in speaking or writing because of the lack of knowledge of collocations or pragmatics. However, the appearance of CALL seems to provide a new outlook for language teaching and learning as well as vocabulary acquisition.

Ever since the advent of computer-assisted language learning (CALL), teachers and researches alike have tried to devise ways in which computer technology can be of use in foreign language classes. Up to now, plenty of research in this regard has been conducted (Makoto, 2006; De, Ridder, 2002; Jeong, 2001; Groot, 2000; Ellis, 1994; Dunkel, 1991).

According to Jones (2000), the availability of many current electronic resources provides numerous opportunities for making texts more comprehensible to learners. Indeed, one of the recent developments in making texts more comprehensible to readers is using computerized glosses or annotations.

Therefore, the major purpose of this study is to examine the usefulness of multimedia glosses in online reading comprehension process and vocabulary learning. Since the concept of glossing is too broad to be investigated within a single study, the effectiveness of only three online computerized gloss conditions (textual, pictorial, and textual pictorial) will be studied. This study also investigates what type of available gloss (textual, pictorial, or a combination) better aids L2 (second language) students to comprehend an online written passage and acquire more vocabulary incidentally.

\section{STATEMENT OF THE PROBLEM}

Even though there are several ways for presenting and introducing new vocabulary in a reading comprehension text, glossing (textual and/or pictorial) have not been appreciated at least in Iranian high schools. It is inevitable for foreign or second language learners to confront new and unfamiliar words in the text they read. Referring to a dictionary and guessing meaning from contextual clues are two commonly used strategies by the learners. Checking the unknown words in a dictionary, specially when the number of new words is high, often interrupts the process of reading and distracts the reader's attention; besides, since there are often several meanings in a dictionary for every word, there is the possibility that the reader chooses the wrong and inappropriate meaning. In the case of guessing or inferencing also it is possible for the reader to make erroneous inferences for similar lexical forms or idioms.

Some researchers report that students who are able to consult glosses before or during the reading process recalled more of the text than those without glossing aids (Davis, 1989; Jacobs et al., 1994). However, this study tries to investigate the effects of different types of gloss (text, picture, and text + picture) on L2 text comprehension, specially when the goal is comprehension of a computerized text in order to have an empirical evidence of such an effect.

\section{OBJECTIVES OF THE STUDY}

This study intended to investigate the effects of exposure to any type of gloss, namely textual, pictorial, and textual plus pictorial, on L2 learner's reading comprehension and vocabulary learning when the goal is exclusively comprehension of an online computerized text.

In other words, the study aimed at examining the usefulness of online textual and/or pictorial glossing on vocabulary learning and reading comprehension ability of L2 learners. By using Mayer's work (1997, 2001, 2002, 2005b) carried out in the field of psychology, this study has addressed the use of textual and pictorial glosses for a meaningful learning. Participants would read a text under four online conditions, (no gloss, text gloss, picture gloss, and text plus picture gloss). These different conditions were used to assess whether any of them would promote comprehension of an online computerized text and vocabulary learning of the target words. Comparing the functions of three mentioned conditions of glossing in reading comprehension and production of target words was another objective of the present study.

\section{RESEARCH QUESTIONS}

According to the stated problem, the following research questions have been addressed in this study:

1. Does exposure to any type of gloss (text, picture, and text plus picture) have a significant effect on L2 readers' comprehension of an online computerized reading text, as measured by a comprehension test?

2. Does exposure to any type of gloss (textual, pictorial, and textual plus pictorial) have a significant effect on L2 readers' learning of online computerized target words, as measured by a production test?

3. Which type of gloss (text, picture, and text plus picture) has a more significant effect on L2 readers' comprehension of an online computerized reading text, as measured by a comprehension test?

4. Which type of gloss (textual, pictorial, and textual plus pictorial) has a more significant effect on L2 readers' learning of online computerized target words, as measured by a production test?

\section{RESEARCH HYPOTHESES}

Based on the questions cited above, this study aimed at testing the following null hypotheses: 
H1. Exposure to any type of gloss (text, picture, and text plus picture) does not have a significant effect on L2 readers' comprehension of an online computerized reading text, as measured by a comprehension test.

H2. Exposure to any type of gloss (textual, pictorial, and textual plus pictorial) does not have a significant effect on L2 readers' learning of online computerized target words, as measured by a production test.

H3. None of the gloss types (text, picture, and text plus picture) have a more significant effect on L2 readers' comprehension of an online computerized reading text, as measured by a comprehension test.

H4. None of the gloss types (textual, pictorial, and textual plus pictorial) have a more significant effect on L2 readers' learning of online computerized target words, as measured by a production test.

\section{METHODOLOGY}

\section{A. Participants}

The population of the participants at the time of the study was 102 female junior high school students studying at Najafabad shahed high school. To assess their general language proficiency level, the standard test of Nelson (2001) was administered. The students' performance on the reading comprehension and vocabulary sections of Nelson test was analyzed to ensure that they were homogeneous in terms of their proficiency level. Only the participants whose scores on this test fell between one standard deviation above and one standard deviation below the mean were selected. Finally, 60 participants were qualified to be included in the study. Later, these homogenized participants were randomly assigned to three experimental groups labeled as textual, pictorial, textual plus pictorial groups, and one control group.

\section{B. Instruments}

\section{Nelson test}

In order to determine the general proficiency level of the participants and to screen them, reading and vocabulary sections of Nelson test (2001), including 30 questions, were used as reliable and valid test for the selection of 60 intermediate participants. The individual scores on these two sections of Nelson were analyzed to ensure that they were of the same level of language proficiency.

\section{Online computerized reading text}

Three appropriate reading passages were selected. It was necessary to determine the readability of the three computerized reading passages the participants were to receive on the day of exposure to the research treatment. The readability level of each computerized reading passage was computed separately by Microsoft Office Word 2007. After matching the readability of the passages to the students' proficiency levels, they were tried out by the selected individuals in the pilot study in order to underline all the unknown words in the passages. Only words underlined by more than half of the participants were selected to be glossed. Based on the result of the pilot study, the passages were computerized, and some words of that computerized written passages were glossed, and hyperlinked by a computer software program called Power Point. The software included different slides that showed computerized reading passages with bold, and underlined words, the definitions of the words, their pictures, and combinations of them. Taking advantage of the results of the pilot study, the pictures exactly related to the meaning of the words were selected. When the participants clicked on the hyperlinked words, a new window appeared and showed the word with a definition in English (textual gloss group), a picture (pictorial gloss group), or a combination (textual plus pictorial gloss group). After receiving the definitions and pictures of the words in a new window, the participants could go back to the passage by clicking again. As can be seen in the following pictures, participants in textual gloss group read a computerized written passage and got access to the definitions of bold, and underlined words in English by clicking on them. Pictorial gloss group got access to their pictures, and mixed gloss group read a computerized written passage by accessing to both definitions and pictures of unknown words. Some examples of the computerized texts along with the hyperlinked words are presented in the following pages.

Example 1: Online computerized reading passage for textual gloss group

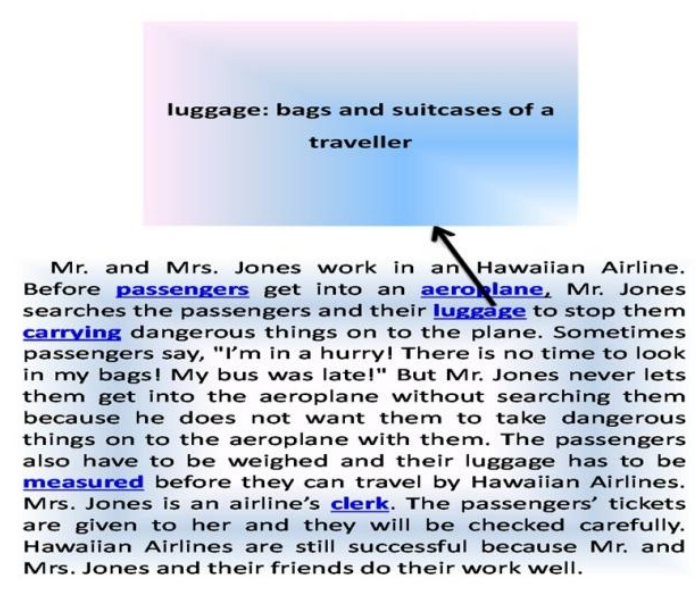


Example 2: Online computerized reading passage for pictorial gloss group
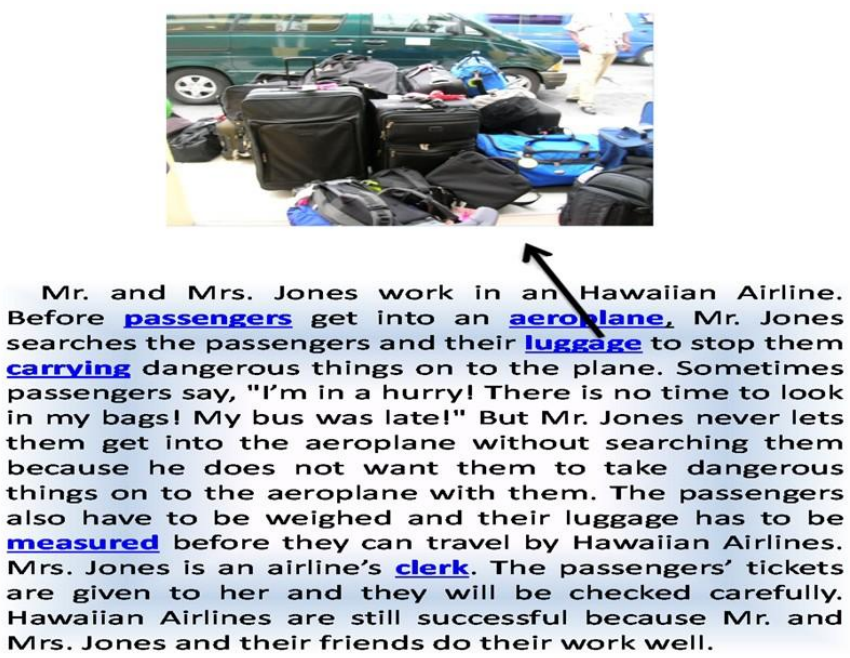

Example 3: Online computerized reading passage for textual-pictorial gloss group

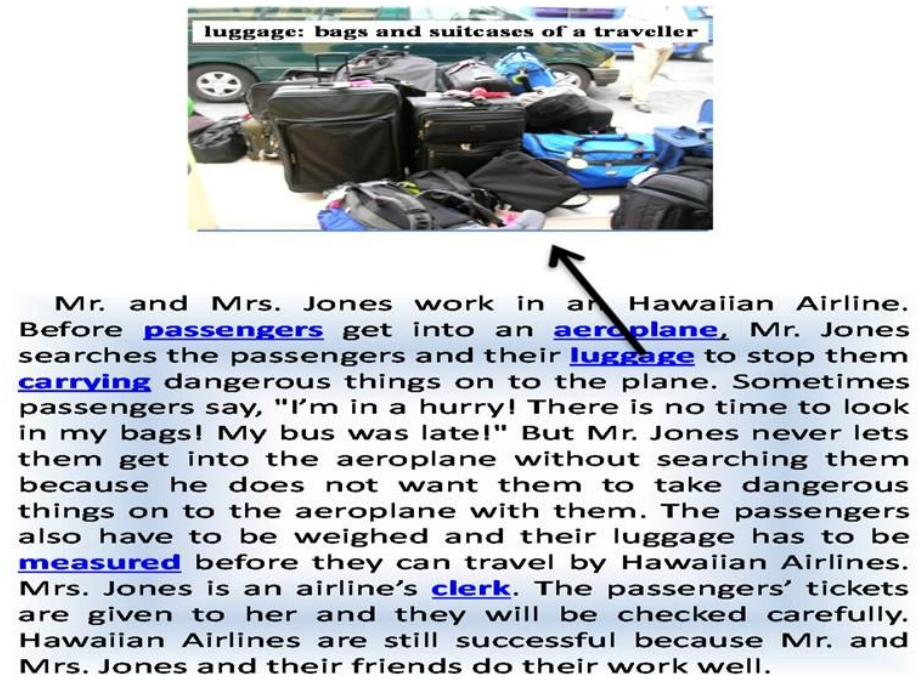

3. Production test

The participants were given three printed paper reading passages with appropriate readability levels followed by a production test. After each written passage was read, the four groups were given the achievement production test. The annotated words in the three computerized reading passages were the focus of the production task. As mentioned in the piloting section, fill-in-the-blanks items were produced by the researcher and a couple of the experts in the field.

4. Comprehension test

After completing the production test, all groups were given an achievement comprehension test consisting of multiple-choice comprehension questions in English. The reliability and validity of the comprehension tests were established. Some specialists in language teaching and testing were asked to review the test, and there was a general consensus among them concerning the content validity of the test.

Participants were allowed to refer back to the passages to answer the comprehension questions if they needed to. In this study, the reading comprehension multiple-choice questions focused on the overall comprehension of the passages, since as the teacher-researcher experienced, comprehension questions should aim at measuring whether students achieve a clear understanding of events happening in the texts.

\section{Procedure}

The present study was conducted in Najafabad Shahed high school computer site. As it was illustrated in the participant section, 60 participants were selected from among a total of 102 participants on the basis of their scores on the standard proficiency test (Nelson, 2001). After the researcher made certain that the participants formed a homogenous sample, they were randomly assigned to one of the four groups; three gloss groups (textual, pictorial, and textual plus pictorial), and a control group. 
On the day of exposure to the research treatment, participants in the three gloss groups received instructions for each gloss conditions. All groups could have access to the texts via internet since the computerized texts, as mentioned earlier, were added to high school computer site for online teaching of reading and vocabulary. Participants were tested individually and they worked through the text at their own pace. This way of teaching was an online process. Textual gloss group read the online computerized written passages having access to the definitions of the glossed words in English. Pictorial gloss group read the online computerized written passages with access to the pictures of the glossed words. Mix gloss group read the online computerized written passages with access to the pictures and the definitions of the glossed words. Control group read the online computerized written texts without having any access to the definitions or pictures of the glossed words.

During the sessions of instruction, the participants had access to online reading passages at high school computer site. As it was mentioned above, the participants in each group worked through the passages under different conditions. The gloss groups could consult glosses by placing the mouse pointer over the colored boldface words. When the participants clicked on the hyperlinked words, a new page appeared and showed the word with a definition in English (textual gloss group), a picture (pictorial gloss group), or a combination of both (textual plus pictorial gloss group). Participants in control group read the texts without having any access to glosses. After completion of the online reading task in different conditions by the participants themselves, the teacher-researcher asked them some questions orally in order to assess whether any of them comprehended the passages and learned the glossed words.

In the next session which was held after four days, three printed paper reading passages followed by the production and comprehension tests were administered to the participants. These three printed paper reading passages are different from the three main online computerized passages of the experiment. But, they included the same key words that were glossed in the three experimental passages and with the same appropriate readability level. Participants read the printed paper passages one by one. After reading each passage, they took a paper version of the production and comprehension tests including 12 questions in the same session. Every passage included 6 fill-in-the-blank production questions, and 6 multiple-choice comprehension questions. The 18 annotated words in the three experimental computerized reading passages were the focus of production tasks. Each computerized passage included 6 annotated words, so each printed paper passage followed by 6 fill-in-the-blank questions.

Participants performed the production tests first so that the multiple choice comprehension tests would not provide additional exposure to the target words, enhancing their recall. The annotated words in the reading texts were the focus of the production tests. Participants were given sentences in English and they were asked to fill in the blanks. They could refer back to the texts to help them find an appropriate word for each blank.

Comprehension tests consisted of multiple-choice comprehension questions in English. Participants were allowed to consult with the texts to help them answer the comprehension questions if they needed to. The multiple-choice comprehension questions dealing with overall comprehension of the texts by considering specific meaning of the words glossed in the experimental texts, aimed at measuring whether participants achieved a clear understanding of events happening in the texts. The participants answered the questions on the answer sheets which were distributed towards the end of the reading task.

\section{DATA ANALYSES}

In the present study, a series of matched $t$-tests were run to compare the mean of each gloss group with that of the control group on the reading comprehension and production tests. One-way ANOVA test was performed to examine if there exist any significant differences among the three gloss groups regarding L2 text comprehension and vocabulary learning. Analysis of variance procedure was followed by Post hoc Scheffe test. This test was run to reveal the level of significant differences among groups.

\section{A. Results of the Reading Comprehension Test for Three Gloss Groups and Control Group}

In order to confirm or reject the first null hypothesis (i.e., Exposure to any type of gloss, text, picture, text plus picture, does not have a significant effect on L2 readers' comprehension of an online computerized reading text as measured by a comprehension test.), first the descriptive statistics of the participants' performance on the comprehension test of 'gloss groups' (text, picture, text plus picture) and 'control group' were calculated. Second, a matched t-test was run to compare the means of the two groups. This test run on the mean scores shows a significant difference between the two means. Table 1. represents the descriptive statistics of the performance of three experimental groups and control group on reading comprehension test.

TABLE 1.

DESCRIPTIVE STATISTICS: PERFORMANCE OF THE FOUR GROUPS ON READING COMPREHENSION TEST

\begin{tabular}{|c|c|c|c|c|c|}
\hline Group & N & Mean & Std. Deviation & minimum & maximum \\
\hline Control & 15 & 5.500 & 1.1952 & 3.5 & 7.0 \\
Text gloss & 15 & 6.367 & 2.1084 & 3.0 & 8.5 \\
Picture gloss & 15 & 6.400 & 1.8439 & 4.0 & 10.0 \\
Mix gloss & 15 & 6.500 & 1.9086 & 4.0 & 9.5 \\
\hline
\end{tabular}


Table 1 illustrates the descriptive statistics of the four groups' scores on text comprehension measures and the total comparison of the scores of the participants among the three gloss groups and the control group. The difference among the means of the gloss groups and control group showed that the annotation groups outscored the control group on comprehension of $\mathrm{L} 2$ texts.

A series of matched t-tests were run on comprehension mean scores to determine whether type of gloss had a significant effect on the reading comprehension. The results are represented in the following Tables.

TABLE 2.

One SAMPle t-Test Results of the COMPREHENSION Test: CONTROL AND TeXT Gloss Groups

\begin{tabular}{|c|c|c|c|c|c|c|}
\hline & \multicolumn{6}{|c|}{ Test Value $=0$} \\
\hline & \multirow[b]{2}{*}{$t$} & \multirow[b]{2}{*}{ df } & \multirow[b]{2}{*}{ Sig. (2-tailed) } & \multirow{2}{*}{$\begin{array}{c}\text { Mean } \\
\text { Difference }\end{array}$} & \multicolumn{2}{|c|}{$\begin{array}{l}95 \% \text { Confidence } \\
\text { Interval of the } \\
\text { Difference }\end{array}$} \\
\hline & & & & & Lower & Upper \\
\hline textual gloss & 11.695 & 14 & .000 & 6.3667 & 5.199 & 7.534 \\
\hline control & .17 .822 & 14 & .000 & 5.5000 & 4.838 & 6.162 \\
\hline
\end{tabular}

As the results of Table 2 show, the difference between the means of the textual gloss group and control group reveals that the participants in textual gloss group outperformed the control group on reading comprehension measures. In order to see if the difference is significant, a matched t-test was run. Since the observed $t$ is greater than the critical $t$ with 14 degree of freedom at the 0.05 level of significance, the first null hypothesis is rejected. The level of significance is .000 $<0.05$, and the difference between the means of two groups is statistically significant.

TABLE 3.

One SAMPLE T-Test Results of THE COMPREHENSION Test: CONTROL AND PICTURE Gloss GROUPS

\begin{tabular}{|c|c|c|c|c|c|c|}
\hline & \multicolumn{6}{|c|}{ Test Value $=0$} \\
\hline & \multirow[b]{2}{*}{$t$} & \multirow[b]{2}{*}{ df } & \multirow[b]{2}{*}{ Sig. (2-tailed) } & \multirow{2}{*}{$\begin{array}{c}\text { Mean } \\
\text { Difference }\end{array}$} & \multicolumn{2}{|c|}{$\begin{array}{c}95 \% \text { Confidence } \\
\text { Interval of the } \\
\text { Difference }\end{array}$} \\
\hline & & & & & Lower & Upper \\
\hline Pictorial gloss & 13.443 & 14 & .000 & 6.4000 & 5.379 & 7.421 \\
\hline control & 17.822 & 14 & .000 & 5.5000 & 4.838 & 6.162 \\
\hline
\end{tabular}

In table 3 , in order to see if the difference between the means of two groups is significant, a matched t-test was run. Since the significance level (.000) is smaller than the alpha level (0.05), and the difference between the means of two groups is meaningful, the first null hypothesis is rejected. Therefore, exposure to picture gloss has a significant effect on L2 readers' comprehension of an online computerized reading text.

TABLE 4.

OnE SAMPle T-Test Results of THE COMPREHENSION TEST: CONTROL AND Mix Gloss Groups

\begin{tabular}{|c|c|c|c|c|c|c|}
\hline & \multicolumn{6}{|c|}{ Test Value $=0$} \\
\hline & \multirow[b]{2}{*}{$\mathrm{t}$} & \multirow[b]{2}{*}{$\mathrm{df}$} & \multirow[b]{2}{*}{ Sig. (2-tailed) } & \multirow{2}{*}{$\begin{array}{c}\text { Mean } \\
\text { Difference }\end{array}$} & \multicolumn{2}{|c|}{$\begin{array}{c}95 \% \text { Confidence } \\
\text { Interval of the } \\
\text { Difference }\end{array}$} \\
\hline & & & & & Lower & Upper \\
\hline textual-pictorial & 13.190 & 14 & .000 & 6.5000 & 5.443 & 7.557 \\
\hline control & 17.822 & 14 & .000 & 5.5000 & 4.838 & 6.162 \\
\hline
\end{tabular}

It can be clearly seen in Table 4 that the amount of $t$-observed is significant at the probability level of $\mathrm{p}=.000$, which is smaller than 0.05 . In other words, the mix gloss group significantly outperformed the control group on reading comprehension measures. Since the significance level (.000) is smaller than the alpha level (0.05), the first null hypothesis is rejected. It can be concluded that multimedia annotations have a beneficial effect on comprehension of L2 texts.

\section{B. The Results of Production Test for Three Gloss Groups and Control Group}

In order to support or reject the second null hypothesis (i.e., Exposure to any type of gloss, text, picture, text plus picture does not have a significant effect on L2 readers' learning of online computerized target words as measured through a production test.), first the descriptive statistics of the participants' performance on the production test of both 'gloss groups' (text, picture, and text plus picture) and 'control group' were calculated. Second, in order to compare the mean of each gloss group with that of control group on the production test, and to find out whether or not there is a meaningful difference between their means, a t-test was run. In Table 5, the descriptive statistics of the performance of three experimental groups and control group on production test are presented. 
TABLE 5.

DESCRIPTIVE STATISTICS: PERFORMANCE OF THE FOUR GROUPS ON PRODUCTION TEST

\begin{tabular}{|c|c|c|c|c|c|}
\hline Group & $\mathrm{N}$ & Mean & $\begin{array}{c}\text { Std. } \\
\text { Deviation }\end{array}$ & minimum & maximum \\
\hline control & 15 & 3.200 & 1.6776 & 0.5 & 6.0 \\
Text gloss & 15 & 5.233 & 1.8791 & 2.0 & 8.5 \\
Picture gloss & 15 & 5.933 & 2.3518 & 2.5 & 10.0 \\
Mix gloss & 15 & 8.100 & 1.5260 & 5.5 & 10.0 \\
\hline
\end{tabular}

Looking at the descriptive data in Table 5, it can be noticed that mean scores of participants in the three gloss groups are different from and higher than the control group indicating that multimedia annotations have affected the production of target words.

A series of t-tests were performed to examine if there exist any significant differences among three gloss groups and control group regarding vocabulary gains.

TABLE 6.

One SAMPle t-Test Results of the Production Test: Control And TeXt Gloss Groups

\begin{tabular}{|c|c|c|c|c|c|c|}
\hline & \multicolumn{6}{|c|}{ Test Value $=0$} \\
\hline & \multirow[b]{2}{*}{$\mathrm{t}$} & \multirow[b]{2}{*}{ df } & \multirow[b]{2}{*}{ Sig. (2-tailed) } & \multirow{2}{*}{$\begin{array}{c}\text { Mean } \\
\text { Difference }\end{array}$} & \multicolumn{2}{|c|}{$\begin{array}{l}95 \% \text { Confidence } \\
\text { Interval of the } \\
\text { Difference }\end{array}$} \\
\hline & & & & & Lower & Upper \\
\hline Textual gloss & 10.786 & 14 & .000 & 5.2333 & 4.193 & 6.274 \\
\hline control & 7.388 & 14 & .000 & 3.2000 & 2.271 & 4.129 \\
\hline
\end{tabular}

As the above table displays, the difference between the means of the groups shows that the participants in text gloss group had better performance than those of control group in vocabulary acquisition measures. In order to see if the difference is significant, a matched t-test was run. Since the significance level (.000) is smaller than the alpha level (0.05), and the difference between the means of two groups is statistically significant, the second null hypothesis is rejected.

TABLE 7.

One SAMPle t-Test Results of the Production Test: CONTROL AND PiCture Gloss Groups

\begin{tabular}{|c|c|c|c|c|c|c|}
\hline & \multicolumn{6}{|c|}{ Test Value $=0$} \\
\hline & \multirow[b]{2}{*}{$t$} & \multirow[b]{2}{*}{ df } & \multirow[b]{2}{*}{ Sig. (2-tailed) } & \multirow{2}{*}{$\begin{array}{c}\text { Mean } \\
\text { Difference }\end{array}$} & \multicolumn{2}{|c|}{$\begin{array}{l}95 \% \text { Confidence } \\
\text { Interval of the } \\
\text { Difference }\end{array}$} \\
\hline & & & & & Lower & Upper \\
\hline Pictorial gloss & 9.771 & 14 & .000 & 5.9333 & 4.631 & 7.236 \\
\hline control & 7.388 & 14 & .000 & 3.2000 & 2.271 & 4.129 \\
\hline
\end{tabular}

As table 7 represents, the difference between the means of two groups is significant. Based on the results presented in the above table, there exists a meaningful difference between the means of picture gloss and control groups in L2 vocabulary learning. Thus, the second null hypothesis is rejected since the level of significant differences between groups is $.000<0.05$.

TABLE 8.

One SAMPle t-Test Results of the Production Test: Control and Mix Gloss Groups

\begin{tabular}{|c|c|c|c|c|c|c|}
\hline & \multicolumn{6}{|c|}{ Test Value $=0$} \\
\hline & \multirow[b]{2}{*}{$t$} & \multirow[b]{2}{*}{ df } & \multirow[b]{2}{*}{ Sig. (2-tailed) } & \multirow{2}{*}{$\begin{array}{c}\text { Mean } \\
\text { Difference }\end{array}$} & \multicolumn{2}{|c|}{$\begin{array}{l}95 \% \text { Confidence } \\
\text { Interval of the } \\
\text { Difference }\end{array}$} \\
\hline & & & & & Lower & Upper \\
\hline textual-pictorial & 11.425 & 14 & .000 & 6.9000 & 5.605 & 8.195 \\
\hline control & 7.388 & 14 & .000 & 3.2000 & 2.271 & 4.129 \\
\hline
\end{tabular}

In table 8 , the difference between the means of the two groups shows that the participants in combination gloss group outperformed those of the control group in vocabulary acquisition measures. In order to see if the difference is significant, a matched t-test was run. Since the significance level (.000) is smaller than the alpha level (0.05), and the difference between the means of two groups is statistically significant, the second null hypothesis is rejected. Therefore, Exposure to text plus picture gloss has a significant effect on L2 readers' learning of target words.

\section{Comparison of Comprehension Test Results of Three Gloss Groups}

In order to confirm or reject the third null hypothesis (i.e., none of the gloss types, text, picture, text plus picture, have a more significant effect on L2 readers' comprehension of an online computerized reading text, as measured by a comprehension test.), first, the descriptive statistics of the participants' performance on the means and standard 
deviations of three gloss groups of reading comprehension test were computed. Second, One-way ANOVA was employed to calculate the amount of variance between and within the gloss groups (text, picture, text plus picture). Third, Post hoc Scheffe test was run to determine whether the difference existing among groups was significantly meaningful for text gloss, picture gloss, and mix gloss.

The descriptive statistics of the three gloss groups' scores on text comprehension measures and the total comparison of the scores of the participants among the three gloss groups were illustrated in Table 1. The difference among the means of three gloss groups on reading comprehension test showed that the pictorial gloss group outperformed the textual gloss group and the combination gloss group outperformed all other groups (textual and pictorial) on this test. The results of ANOVA presented in Table 9 confirm these findings. This test was computed on the production scores to determine whether to determine whether or not type of gloss had a significant effect on the reading comprehension.

TABLE 9

ONE-WAY ANOVA RESULTS OF THE COMPREHENSION TEST FOR THREE GLOSS GROUPS ANOVA

\begin{tabular}{|l|c|r|r|r|r|}
\hline & $\begin{array}{c}\text { Sum of } \\
\text { Squares }\end{array}$ & df & Mean Square & F & Sig. \\
\hline Between Groups & .144 & 2 & .072 & .019 & .981 \\
Within Groups & 160.833 & 42 & 3.829 & & \\
Total & 160.978 & 44 & & & \\
\hline
\end{tabular}

According to the above Table, since the significance level (.981) is greater than the alpha level (0.05), there are no significant differences among the three gloss groups (text, picture, and mix). Therefore, the third null hypothesis is confirmed. As the results suggest, exposure to types of gloss in this study did not appear to have a differential effect on the learners' abilities to comprehend L2 texts. The Post hoc Scheffe test in the following table shows the level of significant differences among the annotation groups.

TABLE 10.

POST HOC SCHEFFE RESULTS OF THE COMPREHENSION TEST FOR THREE GLOSS GROUPS Multiple Comparisons

\begin{tabular}{|c|c|c|c|c|c|c|}
\hline \multirow[b]{2}{*}{ (I) group1 } & \multirow[b]{2}{*}{ (J) group1 } & \multirow{2}{*}{$\begin{array}{c}\text { Mea } \\
\text { Difference(I-J) }\end{array}$} & \multirow[b]{2}{*}{ Std. Error } & \multirow[b]{2}{*}{ Sig. } & \multicolumn{2}{|c|}{$95 \%$ Confidence Interval } \\
\hline & & & & & Lower Bound & Upper Bound \\
\hline tex & picture & -.03333 & .71455 & .999 & -1.7693 & 1.7027 \\
\hline $4 \mathrm{t}$ & $\operatorname{mix}$ & -.13333 & .71455 & .981 & -1.8693 & 1.6027 \\
\hline \multirow[t]{2}{*}{ picture } & tex & .03333 & .71455 & .999 & -1.7027 & 1.7693 \\
\hline & $\operatorname{mix}$ & -.10000 & .71455 & .989 & -1.8360 & 1.6360 \\
\hline \multirow[t]{2}{*}{$\operatorname{mix}$} & tex & .13333 & .71455 & .981 & -1.6027 & 1.8693 \\
\hline & picture & .10000 & .71455 & .989 & -1.6360 & 1.8360 \\
\hline
\end{tabular}

The level of significance for text gloss group and picture gloss group is $.999>.05$, meaning that no significant difference exists between these two gloss groups in reading comprehension test. The level of significance for text gloss group and mix gloss group is .981>.05, which means there is no meaningful difference in the performance of the groups on text comprehension measures. Based on the results of the post hoc test, the level of significance for picture gloss group and mix gloss group is .989>.05. Thus, this conclusion can be drawn that there exists no significant difference between these two groups. The results indicate that no meaningful differences were found among the three gloss types (text, picture, mix) for the reading comprehension test.

\section{Comparison of Production Test Results of Three Gloss Groups}

In order to support or reject the fourth null hypothesis (i.e., none of the gloss types, text, picture, text plus picture, have a more significant effect on L2 readers' learning of online computerized target words as measured through a production test.), first, the descriptive statistics of the participants' performance of three gloss groups of production test were computed. Then, one-way ANOVA was used for the obtained experimental data. This test was run to determine if the difference among the three gloss groups regarding producing target words was significant or not. Finally, Analysis of variance procedure was followed by Post hoc Scheffe test. This test was run to reveal level of significant differences among groups.

As the descriptive data in table 5 show, The difference between the mean scores of the three gloss groups, text, picture, text plus picture, on production measures indicate that the pictorial gloss group outperform the textual gloss group and the combination gloss group outperform the other groups (textual and pictorial) on the production test. Oneway ANOVA was run to determine if the difference among the annotation groups regarding vocabulary learning was significant or not. 
TABLE 11.

OnE-WAy ANOVA Results of THE PRODUCTION TEST FOR THREE GlOSS GRoups

\begin{tabular}{|l|r|r|r|r|r|}
\hline & \multicolumn{1}{|c|}{ ANOVA } \\
& Squares & df & Mean Square & F & Sig. \\
\hline Between Groups & 67.011 & 2 & 33.506 & 8.825 & .001 \\
Within Groups & 159.467 & 42 & 3.797 & & \\
Total & 226.478 & 44 & & & \\
\hline
\end{tabular}

The results obtained from ANOVA test presented in Table 11 confirm a significant difference among participants' production measures in three gloss groups. In other words, since the significance level (.001) is smaller than the alpha level (0.05), there are significant differences among the three gloss groups. Therefore, the forth null hypothesis is rejected.

ANOVA procedure was followed by Post hoc Scheffe test. This test was run to reveal the level of significant differences among the three gloss groups. The details of this post hoc test are presented in Table 12.

TABLE 12.

POST HOC SCHEFFE RESUlTS OF THE PRODUCTION TEST FOR THREE GlOSS GROUPS Multiple Comparisons

\begin{tabular}{|c|c|c|c|c|c|c|}
\hline \multirow[b]{2}{*}{ (I) group2 } & \multirow[b]{2}{*}{$(J)$ group 2} & \multirow{2}{*}{$\begin{array}{c}\text { Mea } \\
\text { Differenge (I-J) }\end{array}$} & \multirow[b]{2}{*}{ Std. Error } & \multirow[b]{2}{*}{ Sig. } & \multicolumn{2}{|c|}{$95 \%$ Confidence Interval } \\
\hline & & & & & Lower Bound & Upper Bound \\
\hline \multirow[t]{2}{*}{ text } & picture & -.70000 & .71151 & .591 & -2.4286 & 1.0286 \\
\hline & $\operatorname{mix}$ & $-2.86667 *$ & .71151 & .001 & -4.5953 & -1.1381 \\
\hline \multirow[t]{2}{*}{ picture } & text & .70000 & .71151 & .591 & -1.0286 & 2.4286 \\
\hline & $\operatorname{mix}$ & $-2.16667 *$ & .71151 & .011 & -3.8953 & -.4381 \\
\hline \multirow[t]{2}{*}{$\operatorname{mix}$} & text & $2.86667 *$ & .71151 & .001 & 1.1381 & 4.5953 \\
\hline & picture & $2.16667 *$ & .71151 & .011 & .4381 & 3.8953 \\
\hline
\end{tabular}

The level of significance for text gloss group and picture gloss group is $.591>.05$, this shows that there is no significant difference between these two glossing conditions in production test. The level of significance for text gloss group and mix gloss group is .oo1<.05, meaning that a meaningful difference exists in the performance of the groups in vocabulary gains. Based on the above Table, the level of significance for picture gloss group and mix gloss group is $.011<.05$, which means that there exists a significant difference between these two groups in producing target words.

The results obtained from Post hoc Scheffe test presented in Table 12. reveal that the mix gloss group significantly outperformed all other groups on the production measures.

\section{DISCUSSION}

Concerning the first research question, results of the present study indicate that the participants exposed to multimedia glosses (textual, pictorial, textual plus pictorial) outperformed those who received no such instruction, and there was a significant difference in the performance of gloss groups and that of control group on the comprehension test. As far as reading comprehension is concerned, the three gloss groups significantly outperformed the control group even though no significant difference among experimental groups was detected. These findings are not surprising and are in tune with the previous findings that have shown reading comprehension to be affected by the inclusion of annotations. Glosses, whether multimedia or traditional have had significant effect on the comprehension of a written text (Davis, 1989; Jacobs, DuFon, \& Hong, 1994; Lomicka, 1998; Bowles, 2004; Mayer, 2005b).

This finding of the study supports the study conducted by Bowles (2004), who employed think-aloud protocols and compared computerized glosses with the traditional ones in vocabulary acquisition and text comprehension measures. The results indicated that both experimental groups, multimedia and traditional gloss groups, had an advantage over the control group in reading comprehension. Along the same lines, in the present study, all groups exposed to glosses outperformed the control group and there was a meaningful difference between the performance of the participants in the gloss groups and those of the control group in comprehension of an online computerized passage.

Considering the second research question, which investigated the effect of types of gloss on production tasks, all groups exposed to glosses outperformed the control group in producing target words. Also a significant difference between the three gloss groups and the control group was found in the production task. These results contradict with the findings of the previous studies that have shown production of target vocabulary items not to be affected by the inclusion of annotations (Chun \& Plass, 1996; Lomicka, 1998; Kost et al., 1999; Bowles, 2004). Participants seemed to focus on text comprehension, leaving aside word morphology or any type of lexical association which would be indicative of processes that might lead to vocabulary acquisition (Bowles, 2004; Lomicka, 1998).

The findings of this study related to the second research question are consistent with the findings of the previous studies (Hulstijn et al., 1996; Watanabe, 1997), in which it is argued that the inclusion of glosses promotes vocabulary 
learning. Both studies conducted by Hulstijn et al. (1996), and Watanabe (1997), however, measured vocabulary learning through recall and post-vocabulary tests only so that any deeper interpretation of those results is not available.

Previous studies carried out by Yeh and Wang (2003), and Yoshii (2006) investigated the effect of different types of multimedia glosses on incidental vocabulary learning. They concluded that providing different types of glosses was effective in the learning of target words. Along the same lines, the present study indicated that all multimedia gloss groups outperformed the control group and a meaningful difference existed between gloss groups and control group in producing target words.

In response to the third research question in which the effect of any types of glosses is investigated related to the computerized text comprehension, the picture gloss group outperformed the text gloss group and the combination gloss group outperformed all the others. In other words, comprehension of the text was better aided by visual and textual information as provided by combination glosses.

As proposed by Mayer $(2001,2005$ b) providing learners with both picture and text glosses so that they could process information through different channels allowed participants to better comprehend the text. Participants in the mix gloss group outscored participants in the text only gloss group and picture only gloss group, but they did not significantly outperform each other. That is, there was no meaningful difference among gloss groups in reading comprehension. It seemed that any type of gloss (text, picture, text plus picture) in comparison with each other did not offer enough support to overall comprehension of the passage.

The results of the current study related to the third research question indicated that the three gloss groups (text, picture, text plus picture) insignificantly outperformed each other respectively on reading comprehension test. This finding supports the previous study conducted by Plass, Chun, Mayer, and Leutner (1998) who investigated the effect of different types of glosses according to the students' preferred mode on text comprehension and learning of the new words. The results of their study provided justification for the generative theory of multimedia learning (Mayer, 1997), an earlier version of Mayer's cognitive theory of multimedia learning (Mayer, 2005b). The participants of their study performed better on the posttests when both visual and textual information were selected, moderate when only one mode was selected, and worse when neither was selected. In addition, participants comprehended the text better when they could choose the gloss in their preferred mode.

Finally, concerning the fourth research question in which the effect of type of gloss on the production task was investigated, the picture gloss group insignificantly outperformed the text gloss group but the combination gloss group significantly outperformed all the others. In other words, a meaningful difference existed in the performance of the combination gloss group and the other two gloss groups in the production of target words.

The finding of this study related to question four confirmed the previous findings (Al-Seghayer, 2001; Chun \& Plass, 1996; Yeh \& Wang, 2003; Yoshii \& Flaitz, 2002). The results of their studies suggested that a combination of textual and pictorial glosses was more beneficial to the learners in vocabulary learning, possibly due to the fact that they received two modes of input (Ellis, 1994), namely verbal and visual.

The outcome of this research that text plus picture group significantly outperformed the text only and picture only gloss groups in producing target words, is interesting and clearly contrasts with the results of the third research question, in which no meaningful difference among any gloss groups (text, picture, text plus picture) in reading comprehension test was found. This seems to indicate that multimedia glosses had a different effect on reading comprehension and vocabulary acquisition. As it is mentioned above, it seems that the three gloss types in comparison with each other do not offer enough support to overall understanding of the passage, but significantly aid in learning target vocabulary items.

In the mix gloss group, where students got a text gloss along with the picture, they did not have to interpret what the picture meant and most of them read aloud the definition given. In other words, most participants took advantage of combination gloss group. The appearance of both text and picture seemed to have a cognitive impact on the participants' vocabulary learning and reading comprehension. However, it eventually only had a significant effect on vocabulary learning, as shown by the quantitative results of the present study.

To sum up, the results of the present study would then provide support for Mayer's cognitive theory of multimedia learning (Mayer, 2001, 2005a, 2005b) and its SLA conceptualization (Plass \& Jones, 2005) that accounts for different channels to process textual and pictorial input. As shown by the quantitative results of this study, better comprehension of computerized reading passage and vocabulary learning occur when both channels (verbal and visual) are engaged.

\section{CONCLUSION}

The findings of the present study demonstrate first that all multimedia gloss groups comprehend online computerized L2 texts significantly better than the control group. Second, Multimedia gloss groups learn the target words better than the control group. There is also a significant difference between multimedia gloss groups and the control group in the production of the target vocabulary items. Third, regarding reading comprehension, the combination gloss group insignificantly comprehend an online computerized L2 text better than all other gloss groups. Finally, regarding vocabulary learning, the combination gloss group significantly outperform the other two gloss groups. 
The results of this study also reflect the fact that utilizing computers and multimedia glosses can be influential in language teaching in general, and online computerized L2 text comprehension as well as incidental vocabulary learning in particular.

To conclude, unlike traditional vocabulary teaching in which learners are exposed to scarce authentic learning material as well as monotonous vocabulary learning method, the integration of CALL to vocabulary learning and reading comprehension can become a dynamic learning process in which ample learning materials from multiple sources, both textual and pictorial, are adopted, and varied learning modes which combines classroom learning with online learning are realized.

\section{REFERENCES}

[1] Al-Seghayer, K. (2001). The effect of multimedia annotation modes on L2 vocabulary acquisition: A comparative study. Language Learning \&Technology, 5(1), 202-232. Retrieved February 7, 2008, from http:// llt. msu.edu/vol5num1/alseghayer/default.html.

[2] Anderson, R. C., \& Freebody, P. (1981). Vocabulary knowledge. In J. T. Guthrie (Ed.), Comprehension and teaching: Research reviews (pp. 77-117). Newark, DE: International Reading Association.

[3] Bogaards, P. (2001). Lexical units and the learning of foreign vocabulary. Studies in Second Language Acquisition, 23(3), 321343.

[4] Bowles, M. A. (2004). L2 glossing: To CALL or not to CALL. Hispania, 87(3), 541-552.

[5] Chodkiewicz, H. (2001). The use of word meanings while reading in English as a foreign language. In S. Foster-Cohen \& Nizegorodcew (Eds.), Eurosla Yearbook (pp. 29-49). Mahvah, NJ: Erlbaum.

[6] Chun, D. M., \& Plass, J. L. (1996). Effects of multimedia annotations on vocabulary acquisition. The Modern Language Journal, 80(2), 183-198.

[7] Chun, D. M. \& Plass, J. L. (1997). Research on text comprehension in multimedia environments. Language Learning \& Technology,1(1), 60-81. Retrieved June 8, 1999, from http:// llt.msu.edu/vol1num1/chun_plass/ default. html.

[8] Davis, J. N. (1989). Facilitating effects of marginal glosses on foreign language reading. The Modern Language Journal, 73(1), 41-48.

[9] De Ridder, I. (2002). Visible or invisible links: Does the highlighting of hyperlinks affect incidental vocabulary learning, text comprehension, and the reading process?. Language Learning \& Technology, 6(1), 123-46.

[10] Dunkel, P. (1991). The effectiveness research on computer-assisted instruction and computer-assisted language learning. In Dunkel, P. (Ed.), Computer-assisted language learning and testing: Research issues and practice. New York: Newbury House/Harper Collins.

[11] Ellis, R. (1994). The study of second language acquisition. Oxford: Oxford University Press.

[12] Groot, P. J. M. (2000). Computer assisted second language vocabulary acquisition. Language Learning and Technology, 4(1), 60-81. Retrieved May 14, 2001, from http://lit.msu.edu/vol4num1/groot/.

[13] Hulstijn, J. H. (1992). Retention of inferred and given word meanings: Experiments in incidental vocabulary learning. In P. J. L. Arnaud \& H. Béjoint (Eds.). Vocabulary and applied linguistics. (pp. 113-125). London: Macmillan.

[14] Hulstijn, J. H., Hollander, M., \& Greidanus, T. (1996). Incidental vocabulary learning by advanced foreign language students: The influence of marginal glosses, dictionary use, and reoccurrence of unknown words. The Modern Language Journal, 80(3), 327-339.

[15] Jacobs, G. M., Du Fon, P., \& Hong, F. C. (1994). L1 and L2 vocabulary glosses in L2 reading passages: Their effectiveness for increasing comprehension and vocabulary knowledge. Journal of Research in Reading, 17(1), 19-28.

[16] Jeong, B. S. (2001). CALL and vocabulary learning: A review. English Linguistic Science, 7, 27-35.

[17] Jones, B. G. (2000). Emerging technologies: Literacies, and technology or trends. Language Learning and Technology, 4(2), $11-18$.

[18] Kost, C. R., Foss, P., \& Lenzini, Jr. J. J. (1999). Textual and pictorial glosses: Effectiveness on incidental vocabulary growth when reading in a foreign language. Foreign Language Annals, 32(1), 89-113.

[19] Krashen, S. (1989). We acquire vocabulary and spelling by reading: Additional evidence for the input hypothesis. Modern Language Journal,73(4), 441-464.

[20] Laufer, B. \& Nation, P. (2001). Passive vocabulary size and speed of meaning recognition: Are they related?. In Foster-Cohen, S. \& Nizegorodcew (Eds.). Eurosla Yearbook (pp. 7-28). Mahvah, NJ: Erlbaum.

[21] Lomicka, L. L. (1998). To Gloss or not to gloss: An investigation of reading comprehension online. Language Learning \& Technology, 1(2), 41-50. Retrieved February 7, 2008, from http://llt.msu.edu/vol1num2/ article2 /default.html.

[22] Makoto,Y. (2006). L1 and L2 glosses: Their effects on incidental vocabulary learning. Language Learning \& Technology, 10(3), 14-21.

[23] Markham, P. (1989). Effects of contextual versus definitional computer-assisted vocabulary instruction on immediate and longterm vocabulary retention of advanced ESL students. Educational Psychology, 9(2), 121-126.

[24] Mayer, R. E. (1997). Multimedia learning: Are we asking the right questions?. Educational Psychologist, 32(1), 1-19.

[25] Mayer, R. E. (2001). Multimedia learning. New York: Cambridge University Press.

[26] Mayer, R. E. (2002). Cognitive theory and the design of multimedia instruction: An example of the two way street between cognition and instruction. In D. F. Halpern \& M. D. Hakel, (Eds.), Applying the science of learning to university teaching and beyond (pp. 55-72). San Francisco: Jossey-Bass.

[27] Mayer, R.E. (2005a). The Cambridge handbook of multimedia learning. New York, NY: Cambridge University Press.

[28] Mayer, R. E. (2005b). Cognitive theory of multimedia learning. In Mayer, R.E. (Ed.), The Cambridge handbook of multimedia learning (pp. 31-48). New York: Cambridge University Press. 
[29] Plass, J. L., Chun, D. M., Mayer, R. E., \& Leutner, D. (1998). Supporting visual and verbal learning preferences in a secondlanguage multimedia learning environment. Journal of Educational Psychology, 90, 25-36.

[30] Plass, J. L., \& Jones, L. (2005). Multimedia learning in second language acquisition. In Mayer, R.E. (Eds.), The Cambridge handbook of multimedia learning (pp. 467-488). New York: Cambridge University Press.

[31] Segalowitz, N., Watson, V., \& Segalowitz, S. (1995). Vocabulary skill: Single -case assessment of automaticity of wordrecognition in a timed lexical decision task. Second Language Research, 11(2), 121-136.

[32] Watanabe, Y. (1997). Input, intake, and retention: Effects of increased processing on incidental learning of foreign language vocabulary. Studies in Second Language Acquisition, 19(3), 287-307.

[33] Yeh, Y., \& Wang, C. W. (2003). Effects of multimedia vocabulary annotations and learning styles on vocabulary learning. CALICO Journal, 21(1), 131-144.

[34] Yoshii, M. (2006). L1 and L2 glosses: Their effects on incidental vocabulary learning. Language Learning and Technology, 10, 85-101.

[35] Yoshii, M. \& Flaitz, J. (2002). Second Language Incidental Vocabulary Retention: The Effect of Picture and Annotation Types. CALICO Journal, 20(1), 33-58.

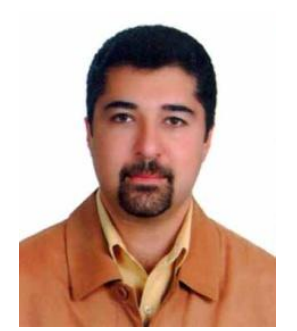

Omid Tabatabaei received his B.A. in translation in 1994 and M.A. in teaching English as a foreign language (TEFL) in 1997, and then his Ph.D in TEFL in 2007. He earned all the mentioned degrees from Iranian Universities.

$\mathrm{He}$ is presently an assistant professor at Islamic Azad University, Najafabad Branch, head of English Department and vice-dean of the Faculty of Humanities and Literature.

He has published a couple of articles at national and international journals and presented papers at national and international conferences. His areas of interest are language acquisition, testing and assessment, teaching skills, and psycholinguistics.

Nasrin Shams received her M.A. in TEFL from Islamic Azad University, Najafabad Branch. She is a high school teacher and at the same time a university instructor. 